\title{
THE ROLE OF INTEGRATED MARKETING COMMUNICATION FOR USTAINABLE DEVELOPMENT IN FOOD PRODUCTION
}

\section{Santa Bormane ${ }^{1}$ Dr.oec.}

${ }^{1}$ Riga Stradins University

\begin{abstract}
The decrease in food production output, the suspension of production, and the decrease in product demand have influenced the operation of producers and their communication with customers in 2020 . This brings to the forefront the producer's role in the use of IMC for sustainable development in Latvia.

The purpose of the survey of leading specialists at Latvian food producers was to find out their opinion on the trends of development and a sustainable use of IMC in business. The object of the research: IMC for sustainable development. The subject: IMC for sustainable marketing at Latvian food producers.

The study uses monographic, quantitative, qualitative methods - interviews of leading specialists of producers. It represents a follow-up to the author's previous studies in the food retail industry where she researched food retail chains and conducted a survey of buyers. She developed a conceptual model of IMC for sustainable business development and found that each sector has peculiarities in product selling, service provision, etc., yet there are also common trends that apply to all industries. The author urges further market research, covering producers.

The results show some trends: 1 ) the motivation to use IMC for sustainable development has grown due to the increased use of technologies; 2) extended periods of sedentarism have exacerbated the problem of overweight in society and given rise to demand for healthy ecological products, including natural ingredients in production; 3 ) the risk of employee illness and the reorganization of production has contributed to the use of digital marketing.
\end{abstract}

Key words: sustainability; sustainable development; sustainable marketing; integrated marketing communication.

JEL code: M14; M31

\section{Introduction}

Background. More and more companies face the challenge of encompassing sustainability in their business, searching for opportunities to integrate in a global sustainable development (Marioka S. N. et.al., 2016). The merging of both fields - sustainable innovations and business - is beneficial and fosters sustainability (Boons F. et. al, 2013). Moreover, these business tools may be adjusted to and structured within companies already in operation. The company may improve its efficiency using a performance assessment system that incorporates the dimensions of sustainable business development combined with elements supporting business sustainability: 1) the production process - the use of technical equipment and manufacturing technologies (capacity, economy, modifiability); 2) the selling process - a strategically reasoned selection of product type and market orientation; 3) the staff management process - a rational and stable provision and coordination of internal structures among structural units; 4) the financial management process - an optimum movement, structure and efficient use of financial resources; 5) the accounting process - an analysis of management functions as basis for decision-making (Ciemleja G., 2010).

Based on the results of the author's previous research on food retail chains and the survey of buyers conducted in 2017-2019, it was concluded that: 1) value proposition may be directly related to product consumption value - quality, ingredients, the manufacturing process, sufficient information, including the re-use and utilisation of packaging, the need for products and the benefits from their use etc.; 2) consumers lack information and competence on product characteristics, which businesses can raise by applying IMC on packaging, labels, informational marking, thus boosting the consumption of sustainable products; 3) IMC focuses on the consumer and its possible behaviour. By implementing IMC through messages and stories, businesses may improve the public's understanding of sustainability and expand the opportunities

1 Email: santa.bormane@gmail.com; mobile phone: +371 26582423 
for people to get involved in the promotion of a sustainable life style; 4) businesses lack understanding of the importance of domestic and ecological products for sustainable development and the influence of the share of imported products upon human health and natural capital; 5) businesses are ready to use IMC tools, which raise consumer awareness of sustainability, in their marketing strategy within the next 3 years as they believe such tools are beneficial to the environment, economy, and social well-being; 6) the national legislation may be conducive to sustainable development if it applies not only to the product seller or consumer, but also to the manufacturer - a mandatory statement of information on the product, its packaging etc. has a role in building the supply of sustainable products, with both the seller and the manufacturer involved; 7) there are in-depth studies of consumers needed that would reveal the emergence of a need for sustainable products and the factors in favour of buying sustainable products (Skiltere D., Bormane S., 2018).

\section{Research results and discussion}

Based on the results of the author's previous research on food retail chains and the survey of buyers conducted in 2017-2019, the author has developed, aggregated and classified IMC tools for sustainability (80 pcs) and divided them into 8 main groups: 1) management IMC tools for sustainability ( 8 pcs); 2) product-related IMC tools for sustainability (14 pcs); 3 ) price-related IMC tools for sustainability (5 pcs); 4) promotion-related IMC tools for sustainability (28 pcs); 5) digital promotion-related IMC tools for sustainability $(12$ pcs); 6) staff professionalism- and selling-related IMC tools for sustainability (2 pcs); 7) corporate identity-related IMC tools for sustainability (6 pcs); 8) geographic placement- and technologyrelated IMC tools for sustainability (5 pcs) (Bormane S., 2018).

The results of the survey of buyers dating back to 2017-2019 show that a key role in buying decisions in the context of sustainable development is played by marketing communication activities pertaining to price discounts on ecological and Latvian-made products, products with environmentally friendly packaging, best-before dates, loyalty system, payment options, staff knowledge and advice, proportion of domestic products etc. This draws attention to the factors of influence upon buyers' decisions.

Seeking to identify the complex factors of influence upon buyers' decisions in the context of sustainable development, the author used the commonly applied principal components method that allows to reduce data dimensions with minimum loss of information and the widespread varimax factor rotation method. Upon grouping IMC tools for sustainable development so as to find the regularities and links among the tools - i.e., what factors buyers possibly pay more attention to in their buying decisions - it becomes evident that the previous trend of the author's classification of IMC tools for sustainable development persists, with product-, promotion- and price-related and digital promotion tools most influential in communication with buyers in the context of sustainable development. Specifically, the author has identified the complex factors that influence buyers' buying decisions in the context of sustainable development. Those can be sorted in the order of importance as follows: 1) product packaging, 2) availability of information, 3) consumer involvement, 4) loyalty system and programmes, 5) availability of results of scientific research, 6) affordability, 7) product quantity and availability, 8) functional product features, 9) company information online.

Based on the above, the conceptual model of IMC for sustainable business development presented in Figure 1 was developed and approved. 


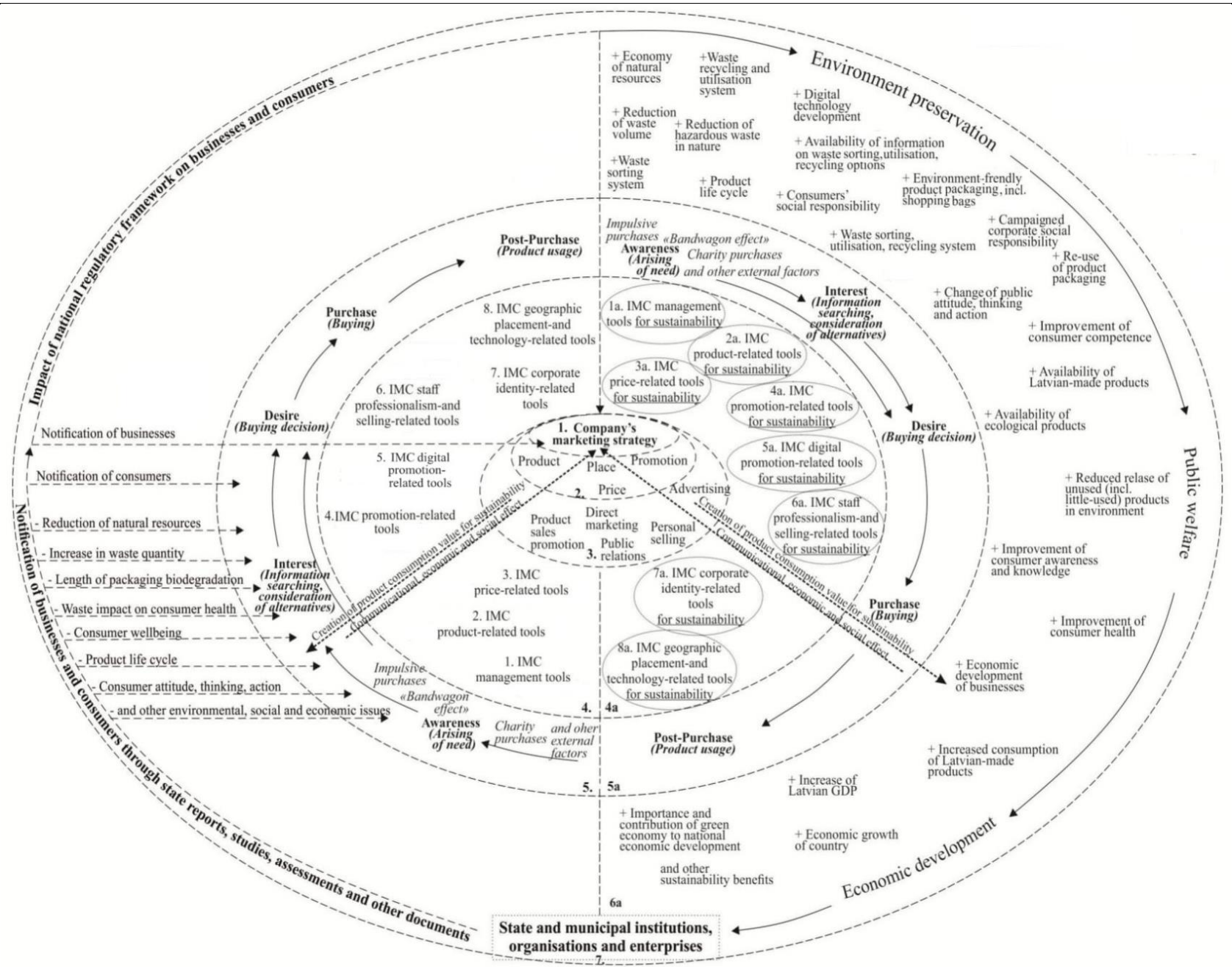

Source: model developed by the author

Figure 1. The conceptual model of IMC for sustainable business development

The specific nature of the conceptual model of IMC for sustainable business development lies in not only IMC tools in companies' communication with consumers and society to achieve their communicational, economic and social goals but also fostering environmental conservation, public wellbeing and economic growth based on organising a different kind of business and a change in public action. A systemic approach to the integration of marketing communication tools and their focusing on the observance of sustainability can not only educate and raise the awareness of businesses and consumers but also create a consumption value, i.e., purchases based on a need (Skiltere D., Bormane S., 2018).

The recent years have seen a major change in the buyers' behaviour, with an increasing tendency of buying decisions being based on other customers' feedback. The buyers' behaviour is determining by searching product information from various online sources. Hence, by placing information on social media and making it possible to browse and compare products, producers or traders can give rise to a positive attitude and behaviour of consumers and draw more visitors to their website or social media page (Pentina I., Tarafdar M., 2014). The author finds that the use of IMC still needs to consider that the social media communication goals need to be focused on delivering and presenting information to consumers, not merely on buying. This would also contribute positively to production - selling - buying decisions in the context of sustainable development. Specifically, there is one goal - more information about the importance of sustainability in economy to encourage the pursuit of such lifestyle. 
In this regard, a growing number of scholars pay attention to the dark side of social media, the possible risks faced by business users and associated with sharing, presence, conversations, identity, relationships, groups, reputation (Baccarella C. V. et.al., 2018).

When it comes to using social media and choosing communication tools, researchers suggest that businesses should experiment and collect data and cases before deciding on their communication strategy and creating an algorithm. As social media destroys many features of members of the public, researchers are urged to focus more on the use of social media, its impact upon individuals, and the cost-benefit ratio for investments in communication.

The author urges further market research, also covering producers that provide the product assortment.

\section{Use of the conceptual model of IMC for sustainable business development in food production}

Since the previous research lead to a conclusion that food retail chains have a motivation to use the IMC tools developed, collected and classified by the author in communication with buyers, and in fact they have been extensively using these IMC tools during the last three years. For instance, 1 ) the proportion of Latvian-made and ecological products in certain food categories is constantly revised and increased, 2 ) there is a more extensive range of products with recyclable packaging, 3) an increasing proportion of products contain information on product healthiness or ingredients with a positive health impact (e.g., nutritional value) through design and/or on the label, 4) gifts on purchase - ecological products etc.

Due to COVID-19 there was a more rapid implementation of digital communication tools by food retail chains in marketing communication with consumers - mobile shopping applications, development or upgrade of web shops, focus on communication on social media and on the web in general and, most prominently, the service of home delivery of food and meals, online payment options. Importantly, as motivated as the product seller - i.e., food retail chains - may be to contribute to sustainable development through their offering of food products, a key role is played by the food producers who supply the retailers with products and are the first link of the supply chain. This brings to the forefront the producer's role in the use of marketing for sustainable development.

The volume of industrial products in Latvia in 2020 fell by $1.7 \%$. This includes food production (Central Statistics Bureau, 2021) where the $3.2 \%$ decrease in production output was predominantly caused by such factors as suspension or outage of production and decrease in product demand due to partners and customers ceasing activity etc. The impact of closed borders upon ingredient (material) deliveries and product export is just partly responsible for the overall production decline. The geographical location of businesses, i.e., the places of production and trading, has become less important due to the COVID-19 restrictions, resulting an increased role of marketing communication in production and trading processes. Producer companies lack funds for advertising costs, but the market conditions where entrepreneurs attempt to adapt to the new situation by moving part of trading to the digital environment in a way benefited the online media. Those suffered the least decline in advertising revenue in $2020-3.3 \%$ (Latvian Advertising Association, 2021).

The economic situation of 2020 has had an impact on the companies' habits in terms of marketing communication. They were forced to switch to an increased use of digital promotion-related IMC tools for sustainability in communication with customers and partners. Creation of safe, effective work environment, emphasizing human oriented approach in contemporary business process management is one of the main conditions for sustainable development of an enterprise (Kalkis H. et.al., 2018).

Hence, in 2020, in order to find out the role of food producers in the promotion of sustainable development, the author followed up on her previous research (2017-2019) and launched an expert survey, 
conducting interviews at Latvian food producer companies (sweet producers). The scientific purpose of the survey of leading specialists at Latvian food producer companies was to find out their opinion on the trends of development at their companies and a sustainable use of IMC in business. In order to find out about the use of the conceptual model of IMC for sustainable business development in food production, the experts were asked what factors affect the use of IMC tools for sustainability.

The results of the research showed that IMC tools for sustainability are usable as sustainable business management tools in the context of sustainable development. While the businesses have not yet used some of the IMC tools in their marketing strategy, those are still considered demand-increasing and conducive to economic development, environment preservation, and public wellbeing. Although the expert interviews are still in progress, one can already notice a trend that food producer companies intend to use IMC tools for sustainability, especially those related to product packaging, design, and information to consumers, especially interactive and digital marketing activities. The experts have also highlighted the importance of product ingredients in the production process. The results of the research show some preliminary trends which are presented below.

The experts from food producer companies predominantly attribute the motivation of using IMC for sustainable development to the rapid increase in the use of the Internet and technologies in daily social processes and business. More specifically, 1) remote work, communication (or life) and shopping online due to the spread of COVID-19, the state of emergency announced in the country, the lockdown, and the general rule of social distancing. Hence, the experts mention digital communication and interactive marketing activities online as the key IMC tools for sustainable development, as those provide a link with the consumer and enable businesses to not only optimise their marketing processes but also to create a dialogue with customers, the public and the market outlets remotely or online. 2) When it comes to communication with the public, food producer companies focus on using social media. However, they admit that there are major differences between the two most popular ones - Facebook and Instagram - in terms of both target audience and content to be published. Furthermore, the expert interviews reveal that food producer companies tend to outsource social media communication and the dialogue with the public to marketing and communication service providers on a contractual basis. The companies admit that the content and methods of communication have substantially changed, with a more prominent role taken by short and interactive subtitled videos that require special knowledge of content creation, implementation and promotion as well as equipment and digital tools. For instance, when communicating on social media, one must not forget about constantly analysing return to find the best-suited tools, technique, time of day and intensity in communication with consumers. The pandemic has brought changes in the established principles in terms of what social media tools - video content, podcasts, live broadcasts, recordings, photos etc. - reach the target audience (the particular generation) more effectively. Since 2020, the situation has become different - elderly individuals, too, are forced to master the use of social media (sometimes via their children and grandchildren), which is why companies devote rather substantial time and resources towards producing appropriate content and making it available to as broad audience as possible (across different categories of age, gender, education, income etc.). Social media as a place of communication has also become a shopping platform. Hence, the volume of information on these sites and Facebook pages of businesses is increasing, as is the need for structuring. Specifically, businesses need to work on making their messages more visible yet distinct, appealing and easily comprehensible through various colours and symbols, for instance, by formatting posts of one kind (such as change of working hours) differently from other content. Thus, instead of spending funds on personnel training, purchases of new technologies etc., specialists are outsourced (photographers, proof-readers, designers, social media administrators, analysts 
etc.). Such decision also stems from the risk of employee illness that has prompted optimisation of daily processes, especially work organisation at such structural units as procurement and marketing departments.

This leads to a conclusion that more and more free agents offer their skills and abilities to several employers for limited periods. They are specialised, highly organised, super connected and able to work from wherever and whenever.

According to the experts, extended periods of sedentarism have exacerbated the problem of overweight in society and given rise to demand for healthy, ecological products. This has lead to more natural ingredients being used in the process of production. Likewise, the progress of lactose and gluten intolerance for the affected individuals prompts producers to work more on promoting new product categories in the market. A key role is therefore played by product packaging, i.e., information on product ingredients, healthiness, nutritional value, as well as recyclable packaging and the variety of types of pre-packaging, given that retailers strive to sell products remotely (contactless ordering, sale, delivery), thus contributing to the increase in the volume of food packaging waste.

The experts unanimously confirm that food producer companies plan to continue applying IMC tools geared towards sustainable development in the years to come despite the challenging economic environment in Latvia and globally, as they believe that using these tools can help change not only the public thinking and action but also the companies' economic habits and methods, thus contributing to the economic development, environmental conservation and social responsibility.

\section{Conclusions}

1) The motivation of using IMC for sustainable development has substantially grown due to the increased use of the Internet and technologies for people's needs in work, study, shopping and other processes.

2) Extended periods of sedentarism have exacerbated the problem of overweight in society and given rise to demand for healthy ecological products, including using natural ingredients in the production process which prompts producers to consider entering new product categories.

3) The risk of employees falling ill and the reorganisation of the production process has contributed to the use of digital and interactive marketing activities. Specifically, more and more free agents offer their skills and abilities to several employers for limited periods. They are specialised, highly organised, super connected and able to work from wherever and whenever.

4) The role of information about product ingredients, healthiness, nutritional value etc. on product packaging has increased. In order to draw consumers' attention, more content needs to published in the digital environment - when addressing consumers on social media, producers need to focus on informing as a marketing communication goal.

5) Given the variety of types of pre-packaging, as traders strive to enable contactless ordering, sale and delivery, it becomes increasingly topical to find new innovative solutions for making the packaging suitable for daily use (not just for recycling or returning to the producer for reuse), for instance, edible, soluble or destroyable without polluting nature.

6) Businesses using social media should consider the negative social impact of social media resulting from the message conveyed, i.e., analyse reachability and feedback when choosing communication tools, with a focus on content quality and being informative. 


\section{Bibliography}

1. Baccarella, C.V., Wagner, T.F., Kietzmann, J.H., McCharty, I.P. (2018). Social Media? It's Serious! Understanding the Dark Side of Social Media, European Management Journal, Volume 36, pp. 431-438

2. Bormane, S. (2018). Integrated Marketing Communications in Sustainable Business, Proceedings of the International Scientific Conference "Society. Integration. Education", Volume 6, pp. 80-96

3. Boons, F., Ludeke-Freund, F. (2013). Business Models for Sustainable Innovation: State-of-the-Art and Steps Towards a Research Agenda, Journal of Cleaner Production, Volume 45, pp. 9-19

4. Central Statistics Bureau. Central Statistics Bureau Database. Retrieved: www.csb.gov.lv. Access: 08.03.2021.

5. Ciemleja, G. (2010). The Sustainable Performance of Small and Medium-Sized Enterprises. Problems and Solutions. Summary of Doctoral Dissertation of Economics and Management, Riga Technical University, p.28

6. Kalkis, H., Roja, Z., Babris, S. (2018). Human Factor and LEAN Analysis at Industrial Manufacturing Plants. Advances in Human Factors, Business Management and Society, pp.274-281

7. Latvian Advertising Association. Latvian Media Advertising Market Review 2020. Retrieved: https://www.Ira.Iv/lv/zinas/latvijas-mediju-reklamas-tirgus-2020-gada-samazinajies-par-16-4. Access: 08.03.2021.

8. Morioka, S. N., Evans, S., Carvalho, M. M. (2016). Sustainable Business Model Innovation: Exploring Evidences in Sustainability Reporting, Procedia CIRP, Volume 40, pp. 659-667

9. Pentina, I., Tarafdar, M. (2014). From "Information" to "Knowing": Exploring the Role of Social Media in Contemporary News Consumption, Computers in Human Behavior, Volume 35, pp. 211-223

10. Skiltere, D., Bormane, S. (2018). The Influence of Integrated Marketing Communications on the Demand of Sustainable Products at Latvian Food Retail Chains, CBU International Conference Proceedings, Volume 6, pp. 441-447

11. Skiltere, D., Bormane, S. (2018). Integrated Marketing Communication as a Business Management Tool in the Context of Sustainable Development, International Scientific Journal "Open Economics", Volume 1(1), pp. $115-123$ 